\title{
Ética na universidade medieval: a importância da leitura dos clássicos para a elaboração de Tomás de Aquino
}

\author{
Tatyana Murer Cavalcante* \\ Terezinha Oliveira**
}

\section{Resumo}

O objetivo deste artigo é tecer considerações sobre a importância da leitura para a elaboração da concepção ética de Tomás de Aquino (1224-5?/1274). Na aurora do século XIII, os citadinos do Ocidente medieval criaram uma nova instituição destinada ao conhecimento e ao ensino: a universidade. Nela, mestres e discípulos debatiam questões fundamentais para a nova sociedade utilizando, sobretudo, textos de filosofia antiga e cristãos, mas também escritos árabes e judeus. As formas literárias utilizadas abarcavam principalmente lectio e disputatio e, por contrapor bases teóricas distintas, aqueles pensadores acabaram por recriar a summa, numa forma original e fundamental para a elaboração filosófica daquele tempo. Para discutir a importância da leitura na elaboração da concepção de ética na universidade medieval serão apresentadas algumas características da produção do conhecimento no século XIII, vinculadas ao seu contexto histórico e, em seguida, debatidas algumas considerações éticas de Tomás de Aquino, um dos mais expressivos autores do período. Considerando os limites deste artigo, apenas um texto do autor, "O objeto da caridade", extraído da sua principal obra, a Suma de Teologia, será debatido em profundidade. Preliminarmente, é possível afirmar que, assim como a leitura dos autores clássicos por Tomás de Aquino e outros mestres do século XIII, os auxiliou a elaborar conhecimentos sobre ética condizentes com seu tempo, a leitura histórica desses autores auxilia na compreensão da atualidade.

Palavras-chave: história da educação, educação medieval, Ensino Superior, leitura e etica, Tomás de Aquino.

\section{Ethics in the medieval university: the importance of classics reading for the elaboration of Thomas Aquinas}

\section{Abstract}

This paper aims to present some considerations about the importance of reading to the development of the ethics conceptions of Thomas Aquinas (1224 - 5? / 1274). At the dawn of the thirteenth century, the townspeople of Medieval West created a new institution designed for knowledge and education: the University.

\footnotetext{
* Doutoranda em Educação, com bolsa Capes, do Programa de Pós-Graduação em Educação da Universidade Estadual de Maringá (PPE/UEM), Maringá, Paraná, Brasil.

${ }^{*}$ Professora Doutora associada da Universidade Estadual de Maringá e bolsista produtividade em pesquisa do CNPq - nível 2. Maringá, Paraná, Brasil.
} 


\section{Tatyana Murer Cavalcante - Terezinha Oliveira}

In it, teachers and disciples were debating key issues for the new society using mainly texts of Ancient Philosophy and Christians, but also Arab and Jewish writings. The literacy forms used encompassed mainly lectio and disputatio, and counteracted by distinct theoretical bases, those thinkers eventually recreated the summa, in a original and fundamental form to the philosophical elaboration of that time. To discuss the importance of reading in the formulation of the concept of ethics in the medieval university, we will present some characteristics of the production of knowledge in the thirteenth century linked to its historical context and then discuss some ethical considerations of Thomas Aquinas, one of the most prominent authors of that period. Considering the limits of this article, only one text, "The object of charity" based on Aquinas major work, the Summa of Theology, will be discussed in depth. Preliminarily, it is possible to state that as well as the reading of classical authors by Thomas Aquinas and other masters of the thirteenth century, helped them develop knowledge about ethics conforming to their time, historical reading of these authors helps in the understanding of today.

Keywords: history of education, medieval education, Higher Education, reading and ethics, Thomas Aquinas.

\section{Introdução}

Este trabalho vincula-se a um estudo mais amplo, no qual investigamos as relações entre educação e ética na elaboração de Tomás de Aquino (1224-5?/ 1274). Entretanto, nosso interesse neste artigo circunscreve-se a uma reflexão sobre a importância da leitura para a compreensão das formulações acerca da ética daquele autor. Por esse motivo, entendemos como essencial partirmos da apresentação de algumas características fundamentais da produção do conhecimento no século XIII, para que possamos apropriar-nos, mais substancialmente, das contribuições do Aquinate em relação ao tema em questão.

Na aurora do século XIII, o Ocidente medieval criou uma nova instituição dedicada ao conhecimento e ao ensino: a universidade. Ela foi filha do renascimento da cidade, ${ }^{1}$ que alargou as possibilidades da vivência humana e exigiu dos homens uma nova forma de organizar-se na coletividade. Essa realidade gerou a necessidade daqueles homens reconsiderarem suas posições teóricas, motivo pelo qual conhecimentos de diferentes campos do saber foram questionados, como o direito, a medicina, a política, a educação e a teologia. Podemos verificar que durante o século XIII a universidade ${ }^{2}$ nascente foi palco privilegiado do debate acerca dos conhecimentos socialmente relevantes.

É sob a perspectiva das relações entre as transformações sociais e a produção do conhecimento que buscaremos compreender o entendimento de ética em Tomás de Aquino, teólogo dominicano e mestre universitário, reconhecido como um dos principais autores da literatura escolástica. 
Ética na universidade medieval: a importância da leitura dos clássicos para a elaboração de Tomás de Aquino

Para que possamos abarcar a relevância da leitura dos clássicos na elaboração sobre a ética no século XIII, partiremos da análise de algumas características da lectio e da disputatio, dois estilos literários essenciais ao período, bem como do debate de aspectos gerais da obra Suma de Teologia, ${ }^{3}$ de Tomás de Aquino, para, em seguida, priorizar a discussão da questão "O objeto da caridade" (TOMÁS DE AQUINO, ST, $\left\|^{\text {a }}\right\|^{\text {ae }}$, q. 25$),{ }^{4}$ oriunda dessa obra, a principal do autor. Como instrumentos para a análise, contaremos com a ajuda de diferentes estudiosos contemporâneos que se dedicam ao tema, notadamente Grabmann (1944), Le Goff (2005), Kenny e Pinborg (1997), Torrell (1999) e Verger (198-?; 2001).

\section{A leitura filosófica no século XIII e a ética em Tomás de Aquino}

A historiografia assinala, com ênfase, a relação entre a produção acadêmica dos séculos XII e XIII e as escolas urbanas e universidades. Em um texto dedicado à literatura filosófica medieval, Kenny e Pinborg (1997) observam que aquela produção esteve intimamente ligada às condições materiais e psicológicas que prevaleciam nessas instituições. Como ensejamos compreender a elaboração ética de Tomás de Aquino, entendemos que relacionar as condições da produção do texto ao próprio texto é um caminho para essa construção.

Conforme já anunciamos, o texto do Aquinate que nos propusemos a analisar é uma das questões debatidas na Suma de Teologia. Essa obra, à qual o autor dedicou cerca de oito anos de sua vida (1266/73-TORRELL, 1999) teria como fito o conhecimento de Deus, não de maneira restrita - Deus em si mesmo -, mas como o princípio e fim de todas as coisas. De acordo com as informações do mestre Dominicano, a obra abarcaria três aspectos que ele julgara como o caminho possível, aos homens, para se compreender Deus: Deus (Primeira Parte), o movimento humano que leva para Deus (Segunda Parte) e Cristo, enquanto modelo de conduta para os homens (Terceira Parte).

A questão que selecionamos, "O objeto da caridade" (TOMÁS DE AQUINO, $S T$, $\left\|^{\mathrm{a}}\right\|^{\mathrm{ae}}, \mathrm{q}$. 25), é oriunda da segunda parte da obra, a mais longa, que discute o caminho para a bem-aventurança. Segundo Grabmann:

A maioria dos pontos de contacto do tomismo com as grandes questões do nosso tempo provêm da secunda pars, onde S. Tomás, ajuntando a genial intuição de um Agostinho ao realismo de um Aristóteles, traça uma síntese geral da moral cristã, com seus caracteres e aplicações de ordem natural ou sobrenatural, individual ou social. (GRABMANN, 1944, p. 127)

Na construção da síntese à qual se refere Grabmann, o Aquinate apresentou e problematizou as virtudes humanas, divididas em teologais, intelectuais, morais e sociais. Para o autor, dentre as virtudes teologais, a caridade era a principal. Embora se tratasse de uma virtude teologal, nosso texto pretende 


\section{Tatyana Murer Cavalcante - Terezinha Oliveira}

demonstrar como a virtude da caridade foi essencial à elaboração ética do Aquinate. Entretanto, para que Tomás de Aquino pudesse estabelecer um conceito de caridade que ultrapassasse os limites teologais e pudesse influenciar decisivamente virtudes morais e sociais, a leitura dos clássicos lhe foi fundamental. Desse modo, para que possamos compreender essa influência, é necessário que não versemos apenas sobre o seu conteúdo, mas também sobre as formas literárias disponíveis àquele mestre e sobre a maneira pela qual a leitura era realizada.

Afirmamos, no início, a íntima relação entre a produção do conhecimento e escolas urbanas no século XII e universidades no século XIII, entretanto precisamos também explicitar a origem desses escritos. Nesse sentido, Kenny e Pinborg (1997) salientam a relevância de considerarmos as formas de ensino ${ }^{5}$ utilizadas no interior das universidades, bem como de compreendermos a distinção entre as duas formas principais: a lectio e a disputatio. Em linhas gerais podemos dizer que a estrutura interna da lectio (conhecida também como lição, leitura ou preleção) dispunha basicamente de quatro partes: (a) leitura em voz alta da Littera; $^{6}$ (b) exposição da disposição do texto, com divisões em partes menores até atingir o nível de proposições simples; (c) a exposição de cada parte, mais ou menos extensa, de acordo com o número de dificuldades a serem conhecidas; $\mathrm{e}$ (d) a parte final, a dubia, dedicada aos pontos mais importantes, apresentados na forma de questões e, posteriormente, disputas (KENNY; PINBORG, 1997, p. 20). Segundo estes autores, a lectio tem uma longa história e suas partes essenciais remetem à Antiguidade. No entanto, destacam que a parte final da lectio parece ter ganho independência e dado origem a uma nova forma de texto ${ }^{7}$ já no século XII, a disputatio (disputa) e, no século XIII, a partir de 1260 , assumiu a forma de comentários independentes, que consistiam em uma série de questões (KENNY; PINBORG, 1997, p. 20).

Ao destacarmos a lectio e a disputatio é preciso salientar que a segunda forma foi ocupando os espaços do ensino a partir da segunda metade do século XII e, principalmente, ao longo do século XIII. É preciso considerar que estas formas de ensinar e aprender foram sendo apresentadas em concomitância com a entrada de textos de filosofia antiga que há séculos eram desconhecidos no Ocidente medieval. Nesse sentido não há como dissociar as formas da leitura, da escrita e do ensino materializados na disputatio, do conhecimento dos autores clássicos antigos. Segundo Verger (198-?), toda a obra de Aristóteles foi traduzida para o latim até meados do século XIII, bem como obras de sábios gregos e comentadores helenísticos árabes (Al-Fârâbi, Avicena, Averróis). Em outra passagem de sua obra, ao debater o final do século XII, Verger afirma que: "A prática da disputa alimentava um autêntico sentido de progresso e a convicção completamente nova de poder chegar a verdades escondidas ou esquecidas, mediante os recursos da razão" (2001, p. 56).

Kenny e Pinborg ressaltam que alguns estudiosos da filosofia medieval consideram a disputatio como uma possibilidade de reconciliar posições 
Ética na universidade medieval: a importância da leitura dos clássicos para a elaboração de Tomás de Aquino

conflitantes: "[...] recentemente foi sugerido que a origem das disputas fosse procurada na produção que adotou a reconciliação das autoridades legais conflituosas pelos canonistas, advogados romanos e igualmente por jurisprudentes islâmicos" (1997, p. 25). ${ }^{8}$ Em outras palavras, até o século XIII, quanto mais complexa se tornava a sociedade e quanto maior a diversidade de concepções teóricas conhecidas, mais se ampliava o espaço do debate.

Segundo Verger: "Mas que a lectio, a disputa (disputatio ou quaestio disputata) era no entanto, no século XIII, o exercício mais novo e mais original da pedagogia universitária" (VERGER, 2001, p. 269). Por sua vez, Kenny e Pinborg também sugerem a possibilidade de lectio e disputatio serem duas facetas do método de estudo orientado para a interpretação de textos e preservação da tradição (KENNY; PINBORG, 1997, p. 25).

Todavia, a nosso ver, ainda que praticadas, concomitantemente, existia uma diferença substancial entre lectio e disputatio, particularmente quanto às suas respectivas finalidades. Enquanto a lição explicitava o texto estudado, em geral, a disputa (inicialmente mera parte da lição) interessava-se por discutir os pontos fulcrais do debate. Ao salientarmos estas diferenças de finalidades entre a lectio e a disputatio objetivamos explicitar as mudanças que ocorreram entre os séculos XII e XIII quanto ao modus de ensinar e aprender. No século XII, com a lectio, existiria uma preocupação em explicar o texto/tema, no século $\mathrm{XIII}$, quando da disputatio, ocorreria um questionar do texto/tema. Entre esses dois séculos estaríamos diante de uma transformação essencial quanto à essência do ensino: de compreender no século XII, passamos para o questionar no século XIII.

Le Goff é um autor que nos auxilia a compreender a disputatio nessa complexidade:

Seria presunçoso pretender definir em poucas linhas o método escolástico. A evolução primordial foi a que levou da lectio à quaestio e da quaestio à disputatio. 0 método escolástico é, em primeiro lugar, a generalização do velho procedimento, empregado notadamente em relação à Bíblia, das quaestiones e responsiones, questões e respostas. Mas colocar problemas, pôr os autores "em questões" (no plural), levou a que fossem colocados "em questão" (no singular). Neste primeiro momento, a escolástica foi o estabelecimento de uma problemática. Passou em seguida a ser um debate, a "disputa", e aqui a evolução consistiu em que, ante o puro argumento de autoridade, o recurso à razão ganhou importância crescente. Enfim, a disputa acabava com uma conclusio, dada pelo mestre. Sem dúvida tal conclusão podia sofrer com limitações pessoais daquele que a pronunciava, e como os mestres universitários tendiam a colocar-se eles próprios como autoridades, a 


\section{Tatyana Murer Cavalcante - Terezinha Oliveira}

conclusão podia ser fonte de uma tirania intelectual. Mas mais do que estes abusos, o que importa é que ela constrangia o intelectual ao engajamento. Ele não podia contentar-se de apenas colocar em questão, mas devia comprometer-se. No extremo do método escolástico estava a afirmação do indivíduo na sua responsabilidade intelectual. (LE GOFF, 2005, p. 346)

Frisamos as palavras de Le Goff quanto à responsabilidade intelectual do mestre, principalmente ao considerarmos que a disputatio exerceu profunda influência no estilo dos trabalhos escritos. No século XIII, muitos comentários passaram a ser escritos sobre a forma de questões disputadas.

A mesma influência a disputatio exerceu sobre as sumas. Antes do século XIII, as sumas eram breves sínteses, de vida efêmera e de conteúdo convencional, entretanto, a partir deste século, passaram a ter uma forma original e se tornaram vitais para a elaboração filosófica da universidade medieval. A Suma de Teologia de Tomás de Aquino é um dos maiores exemplos da importância e vitalidade que a suma adquiriu para o ensino na ambiência universitária medieval. Ela apresenta uma exposição sistemática e clara da doutrina cristã, organizada internamente como "mini disputas" e, segundo seu autor, escrita para iniciantes nos estudos:

O doutor da verdade católica deve não apenas ensinar aos que estão mais adiantados, mas também instruir os principiantes [...]. Por esta razão nos propusemos nesta obra expor o que se refere à religião cristã do modo mais apropriado à formação dos iniciantes. (TOMÁS DE AQUINO, ST, la , prólogo)

Ao assumir papel de relevância no ensino, a suma passa também a influenciar, decisivamente, a disputa e esta, por seu turno, torna-se o eixo central do ensino na universidade medieval. A importância da disputa foi tão significativa que ela passou a se constituir em um dos três principais deveres dos mestres de Teologia, ${ }^{9}$ no século XIII. Ao lado de lecionar e pregar, disputar era uma das atividades acadêmicas mais frequentes do currículo e geralmente as disputas eram publicadas posteriormente sob a forma de coleções de questões disputadas (KENNY; PINBORG, 1997, p. 21).

Para a questão que propusemos a analisar, compreender a importância da disputa é fundamental, pois embora o mestre Tomás tenha escritos de diversos gêneros, a Suma de Teologia é considerada sua obra fundamental.

Segundo Grabmann, a importância da Suma de Teologia do Aquinate quanto à sua forma abarca três aspectos: a supressão de questões, artigos e argumentos inúteis, a supressão da obscuridade e da desordem e, por fim, a supressão das repetições, tão comuns na redação das sumas tradicionais (1944, 
Ética na universidade medieval: a importância da leitura dos clássicos para a elaboração de Tomás de Aquino

p. 48-102). O autor considera ainda a segunda parte da obra como a mais original: "É entretanto a segunda parte a mais original. Sua própria extensão e liberdade de tom constituem, já no ponto de vista do método, um progresso considerável sobre o modo com que se tratavam antes os problemas da moral" (GRABMANN, 1944, p. 91-92).

Ao destacarmos a importância da disputa, a importância das sumas, tivemos como intenção salientar a relevância da Suma de Teologia do mestre Tomás e nela seccionamos, como já mencionado no início, uma breve questão da segunda parte que é "O objeto da caridade" (TOMÁS DE AQUINO, ST, $\left\|^{\mathrm{a}}\right\|^{\text {ae }}$, q. 25). Nesta questão encontramos doze $\operatorname{artigos}{ }^{10}$ que investigavam possíveis objetos do amor cristão e cada um deles foi estruturado como uma "mini disputa". Ou seja, após a pergunta que iniciava o artigo, encontramos duas séries de argumentos, sendo a primeira em um sentido e a segunda em sentido contrário. A seguir, temos acesso à resposta geral do mestre, seguida de respostas individuais à série de argumentos iniciais que finalizavam a questão. Essa última parte era necessária porque geralmente o autor discordava da primeira série de argumentos, tornando indispensável que este expressasse cada discordância.

Em onze dos doze artigos da questão "O objeto da caridade" o autor apresentou três argumentos na primeira série (apenas o sexto artigo contemplava cinco argumentos) e, em todos os artigos, propôs apenas um argumento em sentido contrário.

Voltemo-nos para a questão que trata do objeto da caridade. Em sua elaboração, as fontes que Tomás de Aquino utilizou, conhecidas também como "autoridades", foram a Bíblia, alguns autores da filosofia antiga, principalmente Aristóteles, e pensadores cristãos, notadamente Agostinho, citadas tanto na primeira série de argumentos quanto na série em sentido contrário. Dessa forma, o mestre Dominicano trazia à tona, em cada análise e para cada possível "objeto" da caridade, a elaboração daqueles autores e, a partir dessa apresentação, formulava sua própria solução a respeito de "a quem" a caridade se destinava. Acompanhar a estrutura da questão nos mostra que o ponto central, para o mestre, não era a possível "verdade" de cada fonte, mas a investigação sobre o tema "caridade".

Não adentraremos em cada um dos doze artigos dessa questão porque nosso objetivo é entender o conceito de caridade para o autor. Em questão anterior, Tomás de Aquino já havia definido a caridade como a comunhão entre o homem e Deus, fundamentada numa "amizade", num amor benevolente e recíproco (TOMÁS DE AQUINO, ST, $\left\|^{\mathrm{a}}\right\|^{\text {ae }}, \mathrm{q} .23$, a.1, c.). Dessa forma, todos (e somente aqueles) os possíveis envolvidos na comunhão com a bem-aventurança seriam objetos da caridade (q. 25, a. 10, c.). Dentre os temas tratados nos doze artigos (Deus, o próximo, a própria caridade, os irracionais, a própria pessoa e seu corpo, os pecadores, os inimigos, dos anjos e os demônios), no décimo segundo, o mestre tratou sistematicamente os objetos da caridade. Muito em- 


\section{Tatyana Murer Cavalcante - Terezinha Oliveira}

bora reconhecesse Deus e os anjos como objetos legítimos da caridade, Tomás de Aquino realçou a importância da humanidade na aquisição da bem-aventurança: "Sob esse aspecto, há dois que devem ser amados pela caridade: o homem que se ama a si mesmo, e que ama o próximo" (q. 25, a. 12, c.). Esse é o motivo pelo qual a caridade interessa ao estudo da ética tomasiana. Muito embora ela fosse, segundo o próprio autor, a comunhão entre o homem e Deus, o exercício do amor cristão (a caridade) seria, integralmente, possível na relação entre os homens.

Tomás de Aquino considerava a caridade como a mais excelente das virtudes, porque "[...] a caridade alcança Deus para que nele permaneça" (TOMÁS DE AQUINO, ST, $\left\|^{\text {a }}\right\|^{\text {ae }}$, q. 23 a. 6, c.), ou seja, para o autor, era pela caridade que o homem se movia em direção a Deus. Ao consideramos que 0 grande objetivo da Suma de Teologia era apresentar o movimento humano que levaria a Deus, a caridade ocupa lugar especial neste caminhar, porque ela seria a virtude que possibilitaria esse trajeto. Ao refletir sobre esta virtude, o mestre evidencia a relevância do convívio humano: se amar a si mesmo e ao próximo era condição para atingir a bem-aventurança, ela era também a condição de estabelecimento de um bom convívio social e de ações éticas.

Considerando a convivência humana condição de caridade, portanto elo do amor ao próximo, voltemo-nos aos possíveis objetos "humanos" da caridade: o próximo, o próprio homem, seu próprio corpo, os pecadores e os inimigos. Ao considerar o próximo, segundo o Aquinate, ama-se com caridade um homem pelo que nele há de divino (TOMÁS DE AQUINO, ST, II $\|^{\text {ae }}$, q. 25, a. 1 , c.). Em outras palavras: ama-se Deus amando sua criação, o homem.

A dificuldade estaria em estabelecer que homens poderiam ser assim amados: apenas aqueles que fazem parte de nosso pequeno círculo de amigos? Aqueles com os quais concordamos? Ou também aqueles que têm ideias e atitudes diversas das nossas? Esses limites foram melhores examinados pelos artigos da questão que se dedicaram ao estudo dos pecadores e dos inimigos.

Ao investigar especialmente o caso dos pecadores (TOMÁS DE AQUINO, $S T$, $\left\|^{\mathrm{a}}\right\|^{\mathrm{ae}}, \mathrm{q}$. 25, a. 6), o Aquinate afirmou que se deveria considerar a questão de dois modos: pela natureza e pela culpa. Não se deveria amar os pecados (a culpa) que o homem comete, mas a natureza desse homem, ou seja, sua existência como criatura divina e, portanto, passível de agir bem e conquistar a vida eterna. Quanto ao caso do inimigo (q. 25, a. 8), o autor analisou três possibilidades: 0 inimigo enquanto inimigo, o amor universal pela criatura e o amor a um inimigo em particular. Assim como afirmou, anteriormente, que não se devia amar o pecado, salientou que não se deveria amar o inimigo enquanto inimigo, mas seria necessário amá-lo enquanto criatura capaz de salvação. Ao debater a possibilidade de se amar um inimigo em particular, chegamos mais próximos das ações humanas na elaboração de Tomás de Aquino. 
Ética na universidade medieval: a importância da leitura dos clássicos para a elaboração de Tomás de Aquino

Segundo o autor, se fosse necessário, a caridade exigia que se amasse um inimigo em particular. Entretanto, se não devemos amar o "erro", como considerar esse amor?

Essa consideração nos dirige para uma noção do agir ético na obra tomasiana. No artigo seguinte (TOMÁS DE AQUINO, ST, Ila |lae, q. 25, a. 9), o mestre debateu sobre o que consistiria esse agir, quais "evidências" de amizade se deveria dar aos inimigos. O autor apresentou "provas" mais gerais, como orar por todos, pela comunidade, mas também algumas mais particulares, como não se vingar ou mesmo vencer o mal com o bem, atraindo o inimigo para o amor cristão. Podemos depreender destes argumentos que o mestre nos aconselha a praticar ações que revelem respeito para com o outro, pois esta atitude explicita o grau de civilidade nas relações sociais.

Até este ponto, nossa discussão da questão dedicou-se mais aos aspectos cristãos da elaboração tomasiana, entretanto, explicitemos melhor a contribuição da leitura da filosofia antiga nesse pensamento. Destacamos que o autor definiu a caridade como uma "amizade" entre o homem e Deus. É, pois, justamente a amizade que assegura a contribuição da filosofia clássica à cristã de Tomás de Aquino nessa questão da Suma de Teologia. e o autor buscou em Aristóteles o conceito de amizade. Ao responder se os pecadores amavam-se a si mesmos (TOMÁS DE AQUINO, ST, Ila |lae, q. 25, a. 7), o Aquinate apresentou as condições para a existência da amizade, referindo-se à elaboração aristotélica:

\begin{abstract}
O Filósofo [Aristóteles] o demonstra [não ser possível um pecador amar-se verdadeiramente] pelas cinco condições próprias da amizade. Com efeito, cada amigo: $1^{\circ}$ ) quer a existência de seu amigo, e que ele viva; $2^{\circ}$ ) quer-Ihe bens; $3^{\circ}$ ) faz-lhe bens; $4^{\circ}$ ) vive com seu amigo na alegria; $5^{\circ}$ ) concorda com ele, partilhando suas alegrias e tristezas. Ora, é assim que os bons amam a si mesmos, quanto ao homem interior: querem conserválo na sua integridade; desejam para ele os seus próprios bens, que são os bens espirituais; esforçam-se para que os consiga; com alegria se voltam a seu próprio coração, nele encontrando os bons pensamentos, no presente; a recordação dos bens passados e a esperança dos futuros, que lhes enche de prazer. Semelhantemente, pois sua alma tende para a unidade". (TOMÁS DE AQUINO, ST, $\left\|^{\mathrm{a}}\right\|^{\mathrm{ae}}$, q. 25, a. 7, c.)
\end{abstract}

Dessa forma, ao levar em conta a concepção de Aristóteles, Tomás de Aquino considerou o elemento essencial daquela ética - a amizade - para a aquisição do bem maior dos cristãos - a vida eterna, afirmando a proeminência do convívio ético para a salvação. Se em Aristóteles a boa vida em sociedade justificava a necessidade de ações éticas, a leitura de Tomás de Aquino incorporou aqueles princípios à elaboração cristã, tornando-a mais capaz de auxiliar a 
compreensão de um novo tempo e de um novo modo de vida: o dos homens cristãos citadinos do século XIII, para os quais a vida pública e a convivência social tornavam-se a realidade necessária.

\section{Considerações finais}

Assim, ao refletirmos sobre as mudanças que os homens medievais promoveram em relação ao conhecimento, particularmente quanto à leitura das fontes, entre os séculos XII e XIII, de lectio para disputatio, observamos que os mestres daquele tempo apontavam e realizavam tentativas de construir uma explicação nova, mais condizente com a realidade do século XIII. Com efeito, apesar de nomear suas fontes de "autoridades", os mestres universitários do século XIII e, destacando-se dentre eles Tomás de Aquino, não realizavam um ensino de "verdades" que deveriam ser cultuadas. Ao contrário, compreendemos que aqueles mestres utilizavam os recursos disponíveis para pensarem seu próprio tempo, propondo questões e soluções necessárias à vida citadina que se impunha e esta nova realidade estava expressa na própria escrita do texto.

É sob essa mesma perspectiva que entendemos como essencial a leitura dos clássicos para a elaboração dos saberes em nosso tempo. Não defendemos que devemos copiar-lhes o conteúdo ou a forma da elaboração do saber, mas fazer deles uma leitura histórica e, assim como fizeram os autores medievais, utilizar o conhecimento que a humanidade nos legou como recurso para nos ajudar a criar conhecimentos concernentes ao nosso próprio tempo.

Neste sentido, tratando especialmente da discussão sobre a ética em Tomás de Aquino, compreendemos como fulcral pensarmo-nos como semeIhantes aos nossos concidadãos, assumindo uma ideia de unicidade, tão necessária para entendermos a amplitude de nossos direitos e deveres na vida social.

\section{Referências}

GRABMANN, M. Introdução à suma teológica de Santo Tomás de Aquino. Petrópolis: Vozes, 1944. 156p.

KENNY, A.; PINBORG, J. Medieval philosophical literature. In: KRETZMANN, N.; KENNY, A.; PINBORG, J. (Edit.). The cambridge history of later medieval philosophy. Cambridge: Cambridge University Press, 1997. p. 11-42.

LE GOFF, J. A civilização no Ocidente medieval. Bauru: EDUSC, 2005. 399p.

TOMÁS DE AQUINO. A caridade em si mesma (ST, $\left\|^{\mathrm{a}}\right\|^{\mathrm{ae}}, \mathrm{q}$. 23). In: TOMÁS DE AQUINO. Suma Teológica. São Paulo: Loyola, 2004. v. V, p. 293-309.

O objeto da caridade ( $S T$, $\left\|^{a}\right\|^{a e}$, q. 25). In: TOMÁS DE AQUINO. Suma

Teológica. São Paulo: Loyola, 2004. v. V, p. 336-357. 
Ética na universidade medieval: a importância da leitura dos clássicos para a elaboração de Tomás de Aquino

Prólogo (ST, Ia, prólogo). In: TOMÁS DE AQUINO. Suma Teológica. São Paulo: Loyola, 2001. v. I, p. 135.

TORRELL, J-P. Iniciação a Santo Tomás de Aquino: sua pessoa e sua obra. São Paulo: Loyola, 1999. 460p.

VERGER, J. Cultura, ensino e sociedade no Ocidente nos séculos XII e XIII. Bauru: EDUSC, 2001. 318p.

. Universidades e escolas medievais do final do século $\mathrm{XI}$ ao final do século XV. In: MIALARET, G.; VIAL, J. (Dirs.). História mundial da Educação. Porto (Portugal): RES, [198-?], v. I, p. 261-288.

Notas

${ }^{1}$ A historiografia consagra o renascimento das cidades como parte de um conjunto de profundas transformações no Ocidente medieval, a partir do "Ano Mil". Pela complexidade desse tema não nos cabe aprofundá-lo neste artigo, uma vez que nos afastaríamos de nossos objetivos.

2 O nascimento da universidade também não é tema deste artigo. É necessário apenas apontar que, no século XIII, o grande centro de estudos de teologia era Paris. Para ter acesso inicial à discussão acerca do surgimento da universidade, consultar: ULLMANN, R. A. A universidade medieval. 2. ed. Porto Alegre: EDIPUCRS, 2000, 486p.

${ }^{3}$ Preferimos utilizar o nome Suma de Teologia (Summa Theologiae), por este ser atestadamente o mais antigo e referenciado na literatura medieval (TORRELL, 1999), ainda que a tradução mais recente da obra para a língua portuguesa nomeie-a de Suma Teológica (Summa Theologica).

${ }^{4}$ Sabemos que a norma para a referência em citação obedece ao padrão: (AUTOR, data da publicação utilizada, página); entretanto, para textos medievais utilizamos: (AUTOR, sigla da obra, localização da citação no interior da obra).

${ }^{5}$ Embora não seja objeto desse artigo, consideramos importante ressaltar a relevância e a primazia da oralidade no ensino, pelo menos até a invenção da imprensa (séc. XV). Segundo Kenny e Pinborg, a maior parte da literatura filosófica medieval reflete a prática do ensino (1997, p. 29) e as fontes escritas representam um reflexo limitado de uma cultura oral muito mais rica: "The written records as we have them are only a limited reflection of a much richer oral culture" (KENNY; PINBORG, 1997, p. 17).

${ }^{6}$ Littera corresponde aos livros-texto, aos "manuais", alicerces das disciplinas.

${ }^{7}$ Essa opinião não é consensual: há diferentes hipóteses sobre a origem das disputas e a que expusemos, de acordo com Kenny e Pinborg, foi elaborada por Chenu (1997, p. 25).

8 "[...] recently it has been sugested that the origin of the disputation is to be sought in the procedures adopted to reconcile conflicting legal authorities by canonists, Roman lawyers, and even Islamic jurisprudents" (1997, p. 25).

${ }^{9} \mathrm{~A}$ Teologia era a mais alta das ciências da cristandade, a qual garantia o estudo mais sistemático e aprofundado de Filosofia (KENNY; PINBORG, 1997).

${ }^{10}$ Assim nomeados: 1. "Somente Deus deve ser amado pela caridade, ou também o próximo?"; 2. "A caridade deve ser amada pela caridade?"; 3. "Criaturas irracionais devem ser amadas pela caridade?"; 4. "Podemos nos amar a nós mesmos pela caridade?"; 5. "Deve-se amar seu próprio corpo pela caridade?"; 6. "Os pecadores devem ser amados pela caridade?"; 7. "Os pecadores amam-se a si próprios?"; 8 . "Os inimigos devem ser amados pela caridade?"; 9. "Devemos dar-lhes mostras de amizade?"; 10. "Devem os anjos ser amados pela caridade?"; 11. "E os demônios?"; 12. "Sobre a enumeração do que devemos amar pela caridade" (TOMÁS DEAQUINO, $S T$, \|\|$^{\text {ae }}$, q. 25). 
Tatyana Murer Cavalcante - Terezinha Oliveira

\section{Correspondência}

Tatyana Murer Cavalcante - Rua Lúcia Helena Zampieri, 100, Jd. Boa Esperança, Campinas, São Paulo, CEP: 13091-525.

E-mail: tatyonca@gmail.com - teleoliv@gmail.com

Recebido em 01 de dezembro de 2011

Aprovado em 26 de fevereiro de 2012 